\title{
Clay ingestion enhances intestinal triacylglycerol hydrolysis and non-esterified fatty acid absorption
}

\author{
Caroline Habold*, François Reichardt, Yvon Le Maho, Fabielle Angel, Nicole Liewig, Jean-Hervé Lignot \\ and Hugues Oudart \\ Institut Pluridisciplinaire Hubert Curien, UMR 7178 CNRS-ULP, 23 rue du Loess, BP28, 67037 Strasbourg cedex 2, France
}

(Received 13 June 2008 - Revised 4 November 2008 - Accepted 7 November 2008 - First published online 13 January 2009)

Consumption by animals and humans of earthy materials such as clay is often related to gut pathologies. Our aim was to determine the impact of kaolinite ingestion on glucose and NEFA transport through the intestinal mucosa. The expression of hexose transporters (Na/glucose co-transporter 1 (SGLT1), GLUT2, GLUT5) and of proteins involved in NEFA absorption (fatty acid transporter/cluster of differentiation 36 (FAT/CD36), fatty acid transport protein 4 (FATP4) and liver fatty acid binding protein (L-FABP)) was measured (1) in rats whose jejunum was perfused with a solution of kaolinite, and (2) in rats who ate spontaneously kaolinite pellets during 7 and $28 \mathrm{~d}$. Also, we determined TAG and glucose absorption in the kaolinite-perfused group, and pancreatic lipase activity, gastric emptying and intestinal transit in rats orally administered with kaolinite. Glucose absorption was not affected by kaolinite perfusion or ingestion. However, kaolinite induced a significant increase in intestinal TAG hydrolysis and NEFA absorption. The cytoplasmic expression of L-FABP and FATP4 also increased due to kaolinite ingestion. NEFA may enter the enterocytes via endocytosis mainly since expression of NEFA transporters in the brush-border membrane was not affected by kaolinite. After uptake, rapid binding of NEFA by L-FABP and FATP4 could act as an intracellular NEFA buffer to prevent NEFA efflux. Increased TAG hydrolysis and NEFA absorption may be due to the adsorption properties of clay and also because kaolinite ingestion caused a slowing down of gastric emptying and intestinal transit.

Gastric emptying: Glucose absorption: Intestinal transit: Lipase activity

For thousands of years, people have used clay to heal wounds, soothe indigestion and treat intestinal pathogens. Nowadays, Kaopectate ${ }^{\circledR}$ and Smecta ${ }^{\circledR}$ are common commercial products featuring, respectively, kaolinite and smectite, that assuage diarrhoea in monkeys and humans ${ }^{(1,2)}$. By lining the walls of the intestinal tract, healing clays protect the injured intestinal tract from irritation by toxins. More precisely, the presence of clay in the gut increases mucus secretion by goblet cells and prevents mucolysis through increased protein cross-linking ${ }^{(3)}$.

Clays are microcrystalline minerals and have specific properties such as a layer charge, a high specific surface area (reaching values of about $800 \mathrm{~m}^{2} / \mathrm{g}$ ), a high ion exchange capacity and a high adsorption capacity ${ }^{(4)}$. They may therefore possess a strong nutrient retention power. It has indeed been shown that L-leucine, L-aspartate and D-glucose bind with a high affinity to the clay mineral bentonite ${ }^{(5)}$. In that case, one may ask whether nutrients can be still efficiently absorbed in 'clay-plastered' intestines. On the other hand, also based on their properties, clay minerals could also be an appropriate substratum for enzymes (and should therefore favour hydrolysis of macronutrients and consequently intestinal absorption). Indeed, diosmectite, a natural clay used in the treatment of several gastrointestinal diseases, shows a dose-dependent capacity to adsorb some enzymes in vitro ${ }^{(6)}$. Furthermore, kaolinite feeding in rats has been shown to increase the activity of leucine amino-peptidase and of several dehydrogenases ${ }^{(7)}$.

Kaolinite, one of the simplest clay with an ideal chemical formula of $\mathrm{Al}_{2} \mathrm{O}_{3} \cdot 2 \mathrm{SiO}_{2} \cdot 2 \mathrm{H}_{2} \mathrm{O}$, is usually the main clay provided to humans suffering from diarrhoea ${ }^{(8-11)}$. In systemic mineralogy, kaolinite belongs to the category of phyllosilicates, which are stratified layered minerals. Because of the strong attractions between the layers, most reactivity of kaolinite is controlled by the external adsorption surface area of the particles. Kaolinite easily adsorbs water ${ }^{(12,13)}$ and is known to selectively bind some noxious compounds in the digestive tract and to avoid their absorption by enterocytes. Among these substances, diarrhoea-causing enterotoxins, plant metabolites $^{(14)}$ and aflatoxins ${ }^{(15)}$ have been shown to be adsorbed by kaolinite and, consequently, may not cross the intestinal barrier. However, there is a lack of studies describing the interactions between kaolinite and dietary macronutrients, except that of Dowling et al. ${ }^{(16)}$. These authors showed increased intestinal glucose uptake in rats fed with diets containing 66 and $80 \%$ kaolinite powder, although there was no hypertrophy of the small intestine. Unfortunately, they did not look at further possible mechanisms, i.e. expression of

Abbreviations: CD36, cluster of differentiation 36; L-FABP, liver fatty acid binding protein; FAT, fatty acid transporter; FATP4, fatty acid transport protein 4; SGLT1, Na/glucose co-transporter 1.

* Corresponding author: Dr Caroline Habold, fax + 3338810 6273, email caroline.habold@c-strasbourg.fr 
glucose transporters, since these had not yet been characterised in 1967. These mechanisms are now well described: glucose is absorbed at the apical side of the enterocytes either through an energy-dependent $\mathrm{Na} /$ glucose co-transporter 1 (SGLT1) when its concentration in the lumen does not exceed $30-50 \mathrm{~mm}^{(17)}$, or through the facilitative GLUT2 at higher concentrations ${ }^{(18,19)}$. Glucose is transported out of the enterocyte through GLUT2 (which is also located in the basolateral membrane) and diffuses 'down' a concentration gradient into capillary blood within the villus ${ }^{(20)}$. The blood passes into the mesenteric vein and then into the hepatic portal vein, which delivers nutrients to the liver.

In addition to glucose, it would also be of great interest to investigate whether intestinal TAG absorption could be affected by clay ingestion. Before absorption, TAG molecules are hydrolysed according to a two-step process. First, emulsification occurs: large aggregates of dietary TAG, which are virtually insoluble in an aqueous environment, are broken down physically and held in suspension. Second, TAG molecules are digested by pancreatic lipase (a water-soluble enzyme; $E C$ 3.1.1.3) to yield monoacylglycerol and NEFA, both of which can efficiently diffuse or be transported into the enterocyte. Fatty acid transport protein 4 (FATP4), fatty acid transporter/cluster of differentiation 36 (FAT/CD36) and plasma membrane fatty acid binding protein (L-FABP) mediate NEFA uptake by the small intestine ${ }^{(21-24)}$. L-FABP and FATP4 are also located in the cytoplasm where they bind NEFA and therefore prevent their efflux in the lumen $^{(23,25)}$. Once inside the enterocyte, NEFA and monoacylglycerol are re-synthesised into TAG, and are then packaged with cholesterol, apolipoproteins and other lipids into chylomicrons. Chylomicrons are transported to the basolateral membrane, where they undergo exocytosis and are then transported into the lymphatic system, which rapidly flows into the blood. Blood-borne chylomicrons are rapidly disassembled and their constituent lipids utilised throughout the body.

The aim of the present study was to determine the impact of kaolinite ingestion on the transport of glucose and NEFA through the intestinal mucosa. Therefore, the gene and protein expression of SGLT1, GLUT2, GLUT5 (an apical fructose transporter), FAT/CD36, FATP4 and L-FABP were measured (1) in rats whose jejunum was perfused with a solution of kaolinite, and (2) in rats who spontaneously ate kaolinite pellets during 7 and $28 \mathrm{~d}$. Also, we determined TAG and glucose absorption in the kaolinite-perfused group, and pancreatic lipase activity, gastric emptying and intestinal transit in rats who received kaolinite by oral administration. For the intestinal perfusion and oral administration experiments, the amount of kaolinite administered was similar to that provided to humans in the treatment of digestive disease and adjusted to rat body mass.

\section{Experimental methods}

\section{Animals}

Male Wistar rats weighing $300 \mathrm{~g}$ were obtained from Iffa-Credo (Lyon, France). Animals were housed individually in leucite cages and maintained at $23^{\circ} \mathrm{C}$ with a $12 \mathrm{~h}$ light period. They were fed a standard diet (A03 pellets; UAR, Epinay-sur-Orge, France) and had free access to water throughout the experiment. They were weighed every day between 09.00 and 10.00 hours. The experiment complied with the 'Principles of Animal Care' publication no. 86-23, revised 1985 of the National Institute of Health, and with current legislation (L87-848) on animal experimentation in France. Commercial kaolinite powder (Argiletz, Lizysur-Ourcq, France) was used for all the different experiments.

\section{Experimental procedures}

Oral administration of kaolinite. After 1-week acclimatisation, the rats had free access to kaolinite, food and water during 7 or $28 \mathrm{~d}$. Kaolinite was not mixed with food but prepared as compact blocks similar in size to the standard food pellets and given ad libitum as separate kaolinite pellets together with the normal A03 pellets. 'Control' rats had only food and water during the same periods. After these 7 and $28 \mathrm{~d}$ periods, rats weighing 361.9 (SEM 17.5) g (control rats after $7 \mathrm{~d}$ ), 365.2 (SEM 12.5) g (kaolinite-supplemented rats after $7 \mathrm{~d}$ ), 446.8 (SEM 16.3) g (control rats after $28 \mathrm{~d}$ ) and 439.5 (SEM 19.7) g (kaolinite-supplemented rats after $28 \mathrm{~d}$ ) were killed by decapitation; their jejunum $(15 \mathrm{~cm}$ extending from the ligament of Treitz) was removed and treated for Northern and Western blotting. As there were no significant differences between control rats killed either after $7 \mathrm{~d}$ or $28 \mathrm{~d}$, we pooled the Northern and Western blotting results. TAG concentration was measured in the troncular blood (Randox kit TR213; Randox Laboratories Ltd, Crumlin, UK).

For the three experiments below, rats weighing 422.1 (SEM 21.5) $\mathrm{g}$ were food-deprived the night before the beginning of the experiment.

Oral administration of rats with kaolinite and olive oil. The rats received by oral administration $3 \mathrm{ml}$ saline solution containing $0.02 \mathrm{~g}$ kaolinite or $3 \mathrm{ml}$ of saline solution (controls), and $1.5 \mathrm{ml}$ olive oil immediately after. They were killed $30 \mathrm{~min}$ later and the intestinal luminal content was collected for measurement of lipase activity.

Gastric emptying and intestinal transit. Gastric emptying time and intestinal transit were determined using methylene blue as tracer dye ${ }^{(26)}$. Briefly, rats were orally administered with $3 \mathrm{ml}$ saline solution containing $0.02 \mathrm{~g}$ kaolinite or only $3 \mathrm{ml}$ saline solution (controls), and immediately after, with $1 \mathrm{ml}$ methylene blue $/ 10 \%$ sucrose solution and euthanised at $30 \mathrm{~min}$ after oral administration. The stomach was clamped above the oesophageal sphincter and below the pylorus to prevent leakage of the dye. Stomachs were cut and immediately homogenised in $10 \mathrm{ml} 0 \cdot 1 \mathrm{M}-\mathrm{NaOH}$. After clearing steps by centrifugation, optical density at $562 \mathrm{~nm}$ of the supernatant fraction was determined. Gastric emptying was determined as the difference between the measured optical density and that of a group of rats, orally administered in parallel and euthanised at $1 \mathrm{~min}$ after oral administration. Intestinal transit was determined as the most distal point of migration of methylene blue in the intestine and expressed as a percentage of the total length of the intestine.

Intestinal perfusion of kaolinite, Intralipid ${ }^{\circledR}$ and glucose solutions. Rats were anaesthetised before surgery using intraperitoneal administration of ketamine $(150 \mathrm{mg} / \mathrm{kg}$ body mass; Imalgene, Merial, France) and placed on a heated $\left(37^{\circ} \mathrm{C}\right)$ surgical table. After performing a laparotomy, the small intestine was isolated and the luminal contents removed 
by gently flushing with saline solution at $37^{\circ} \mathrm{C}$. An intestinal loop $(15 \mathrm{~cm}$ extending from the ligament of Treitz) was cannulated to allow a recirculating perfusion at $37^{\circ} \mathrm{C}$ at a flow rate of $2 \mathrm{ml} / \mathrm{min}$ with either $15 \mathrm{ml}$ saline solution containing $0.02 \mathrm{~g}$ kaolinite or with saline solution alone (controls). After $30 \mathrm{~min}$, the first perfusion solution was replaced by a second one composed of $15 \mathrm{ml}$ Intralipid $^{\circledR}$ solution (4\%) (containing $40 \mathrm{~g}$ fractionated soya oil, $9 \mathrm{~g}$ glycerol and $6 \mathrm{mmol}$ phosphate per litre; Pharmacia, St-Quentin-en-Yvelines, France) at $37^{\circ} \mathrm{C}$ containing $5 \mathrm{~mm}$-glucose. The animals were finally killed after an absorptive period of $20 \mathrm{~min}$. The small intestine was excised and the mucosa was scraped free of the underlying tissue, weighed and treated for Northern and Western blotting. Glucose concentration was estimated in the luminal content using a glucose oxidase-peroxidase kit (Roche Diagnostics, Mannheim, Germany). Absorption rate was calculated from the difference between the total amount of glucose injected initially and that collected at the end of the experiment. Blood glucose concentration was also measured in the hepatic portal and caudal veins before and after luminal perfusion. TAG and NEFA concentrations were estimated in the luminal contents as described previously ${ }^{(26)}$. Blood TAG concentration was measured in the caudal vein.

\section{Northern blot analysis}

Total RNA from jejunal mucosa was isolated by the method of Chomczynski \& Sacchi ${ }^{(27)}$. Of total RNA, $5 \mu \mathrm{g}$ was electrophoresed per lane in an agarose gel. After electrophoresis, RNA was transferred to a nylon membrane (Roche Diagnostics, Mannheim, Germany) by vacuum blotting and then fixed to the membrane by UV light. Blots were probed with specific digoxigenin-end-labelled $\left(5^{\prime}\right)$ antisense oligonucleotide probes (Table 1; Eurogentec, Seraing, Belgium) using the method of Trayhurn et al. ${ }^{(28)}$. Slot-blots were stripped and re-probed with an $18 \mathrm{~S}$ rRNA probe (Table 1) to correct for variations in RNA loading or blotting. Blots were analysed by densitometry using the Gene Tools software (Syngene, Frederick, MD, USA).

\section{Reverse transcriptase polymerase chain reaction analysis}

cDNA was synthesised from $2 \mu \mathrm{g}$ total RNA in $25 \mu \mathrm{l}$ reaction buffer (Finnzymes OY, Espoo, Finland) containing $1 \mu 1$ of avian myeloblastosis virus RT (Finnzymes OY, Espoo,
Finland), oligo $(\mathrm{dT})_{17}$ primer $(50 \mathrm{pm}$; Eurogentec, Seraing, Belgium) and 0.2 mM-deoxynucleotide triphosphate (Promega, Madison, WI, USA) $\left(60 \mathrm{~min}\right.$ at $\left.42^{\circ} \mathrm{C}\right)$. cDNA was then amplified by PCR using specific primers (Table 1). The PCR reactions were carried out in $10 \mu$ l Red'Y'StarMix (Eurogentec, Seraing, Belgium) diluted to a final volume of $20 \mu \mathrm{l}, 1 \mu \mathrm{M}$ of each primer and $1 \mu \mathrm{l}$ of the cDNA mixture. cDNA were amplified for a determined number of cycles (Table 1) as follows: hot starting for $10 \mathrm{~min}$ at $95^{\circ} \mathrm{C}$, denaturation for $45 \mathrm{~s}$ at $94^{\circ} \mathrm{C}$, annealing at $50^{\circ} \mathrm{C}$ for $45 \mathrm{~s}$, and elongation at $72^{\circ} \mathrm{C}$ for $45 \mathrm{~s}$. PCR products were resolved on a $2.5 \%$ agarose gel and visualised by ethidium bromide staining. The staining intensity was evaluated using the Gene Tools software (Syngene, Frederick, MD, USA). Results were expressed as relative densitometric units, normalised to the values of a phosphoribosomal protein (acidic ribosomal phosphoprotein P0; Arbp) mRNA used as an internal control.

\section{Western blot analysis}

Brush-border membrane proteins were separated from other intestinal mucosal proteins as described by Schmitz et al. ${ }^{(29)}$. Protein concentrations were determined using the RcDc assay from Bio-Rad Laboratories (Hercules, CA, USA). Western blotting was conducted using standard techniques ${ }^{(30)}$. Proteins (40 $\mu \mathrm{g}$ per lane) from the brush-border membrane or other mucosal proteins were separated by SDS-PAGE using either 7 or $12 \%$ poly-acrylamide gels and electroblotted onto polyvinylidene fluoride membranes before immunodetection processing. The membranes were incubated with the primary antibody (rabbit anti-rat SGLT1, GLUT5, GLUT2 (Chemicon, Temecula, CA, USA), rabbit anti-L-FABP (Genetex, San Antonio, TX, USA), rabbit anti-FATP4 (Santa Cruz Biotechnology, Santa Cruz, CA, USA)) and then with a horseradish peroxidase-conjugated secondary antibody. The bound antibodies were visualised by incubating the blots in West Pico (Pierce, Rockford, IL, USA). The level of immunoreactivity was then measured as peak intensity using an image capture (Genegnome; Syngene, Frederick, MD, USA) and analysis system (Gene Snap and Gene Tools; Syngene). The membranes were secondarily stripped and incubated with an anti- $\beta$-actin antibody (Sigma Aldrich, St Louis, MO, USA) to correct for variations in protein loading or blotting. Results for each transporter were expressed as relative densitometric units, normalised to the values of $\beta$-actin.

Table 1. Synthetic oligonucleotides and experimental conditions used in Northern blotting and RT-PCR analysis

\begin{tabular}{|c|c|c|c|}
\hline Gene & Sequence & GenBank number & Cycling number \\
\hline $18 \mathrm{~S}$ & 5'-CGCCTGCTGCCTTCCTTGGATGTGGTAGCCG-3' & M11188 & \\
\hline SGLT1 & 5'-TGCCAGTCCCCCTGTGATGGTGTAAAGGGCGG-3' & D16101 & \\
\hline GLUT5 & 5'-GGACTGGGCCCCACGGCGTGTCCTATGACGTA-3' & L05195 & \\
\hline GLUT2 & 5'-CCGCCCCGCCTTCTCCACAAGCAGCACAGAGA-3' & J03145 & \\
\hline L-FABP & 5'-GCGGTCAGCCATGCCTTTCACCTCCTGCAACC-3' & M18467 & \\
\hline FAT/CD36 & 5'-CACAGCCAGGACAGCACCAATAACGGCTCC-3' & AF111268 & \\
\hline Arbp & $\begin{array}{l}\text { 5'-GTTCACCAAGGAGGACCTCA-3' } \\
\text { 3'-AGACACCTCTGCCTAATGTG-5' }\end{array}$ & NM_022402 & $23-25$ \\
\hline FATP4 & $\begin{array}{l}\text { 5'-AAGACAGAGTTGCGGAAGGA-3' } \\
\text { 3'-GTTCCGGTCTGGTTTCGATC-5' }\end{array}$ & XM_001079409 & 25 \\
\hline
\end{tabular}

SGLT1, Na/glucose co-transporter 1, FABP, fatty acid binding protein; FAT, fatty acid transporter; CD36, cluster of differentiation 36; Arbp, acidic ribosomal phosphoprotein P0; FATP4, fatty acid transport protein 4. 


\section{Statistical analysis}

Data are presented as mean values with their standard errors. Statistical comparisons of experimental data were performed by one-way ANOVA and Tukey's post hoc test by using the software SigmaStat (Jandel Scientific, San Rafael, CA, USA). The level of statistical significance was set at $P<0 \cdot 05$.

\section{Results}

Intestinal glucose and non-esterified fatty acid uptake following kaolinite perfusion

The jejunum of rats was perfused in vivo with saline solution (control group) or saline solution containing $0.02 \mathrm{~g}$ kaolinite (kaolinite group) and then with Intralipid ${ }^{\circledR}$ solution containing $5 \mathrm{~mm}$-glucose. We measured the uptake of glucose by the jejunum after kaolinite perfusion, and we quantified the mRNA level and the amount of protein of the hexose transporters SGLT1, GLUT2 and GLUT5. Rates of glucose uptake in the jejunum were not significantly different between control and kaolinite-perfused animals (0.28 (SEM 0.02) v. 0.23 (SEM 0.03) $\mu \mathrm{mol}$ glucose/mg mucosa per $\min (P=0.080)$, respectively). Furthermore, the portal and systemic glycaemia of rats of both groups did not vary significantly after the perfusion (data not shown). Finally, perfusion of the jejunum with kaolinite did not affect the expression pattern of SGLT1, GLUT2 and GLUT5 (data not shown).
As for glucose, we measured the uptake of NEFA by the jejunum after intestinal perfusion with kaolinite and then with Intralipid $^{\circledR}$ solution containing $5 \mathrm{~mm}$-glucose. Between the beginning and the end of the perfusion of Intralipid ${ }^{\circledR}$ solution, TAG concentration in the perfusate showed a 40.0 and $56.7 \%$ decrease in the control and kaolinite groups, respectively (Fig. 1(a)). In parallel, the rate of NEFA uptake was 1.8-fold higher in the kaolinite than in the control group (Fig. 1(b)). However, we did not observe any significant difference in plasma TAG concentration after $20 \mathrm{~min}$ perfusion of Intralipid $^{\circledR}$ solution between the kaolinite and the control group (Fig. 1(c)). In order to characterise the mechanisms involved in increased NEFA uptake after kaolinite perfusion, we looked at the expression of the NEFA transporters FAT/ CD36, L-FABP and FATP4 after kaolinite intestinal perfusion and ingestion (Figs. 1(d), (e) and (f)). Intestinal perfusion with kaolinite in saline solution during $30 \mathrm{~min}$ affected neither the gene expression (Figs. 1(d), (e) and (f)) nor the protein level (data not shown) of these transporters.

\section{Expression of hexose transporters after long-term kaolinite feeding}

When given ad libitum during 7 and $28 \mathrm{~d}$, all the animals consumed kaolinite deliberately: $1 \cdot 1$ (SEM 0.4) g/d ( $n$ 8), representing approximately $4 \%$ of the total amount (food + kaolinite, w/w) they ingested every day. Food consumption (a)

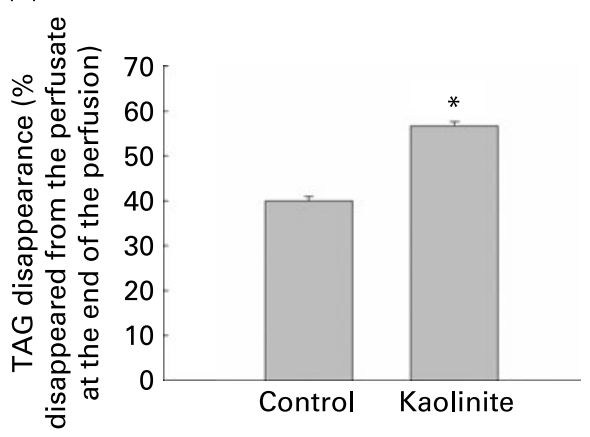

(d)

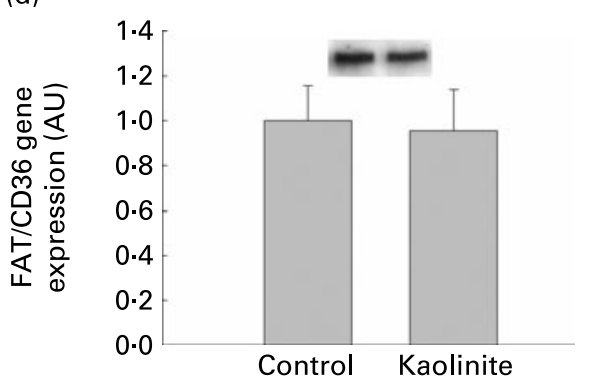

(b)

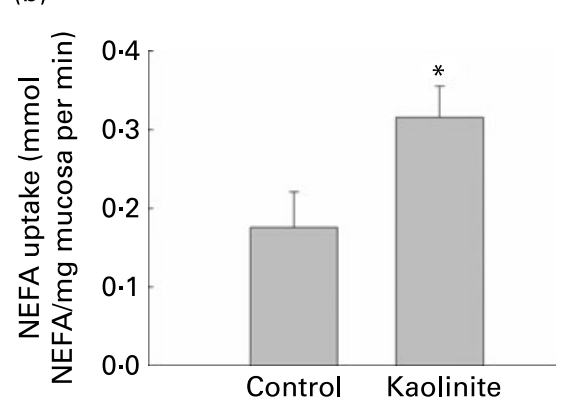

(e)

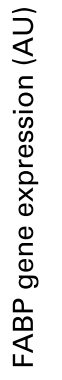

(c)

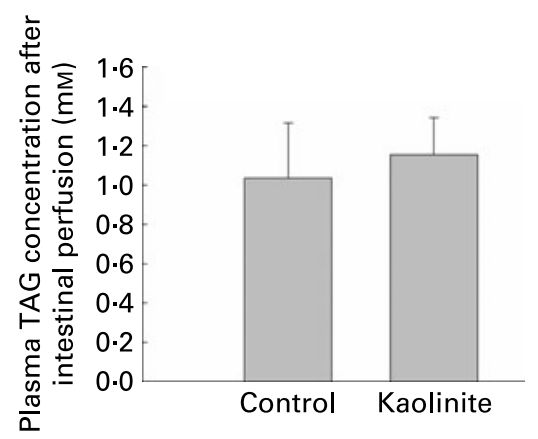

(f)

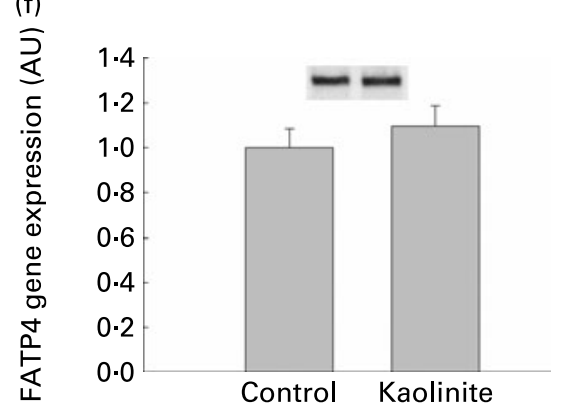

Fig. 1. Rates of NEFA uptake in the jejunum and gene expression of NEFA transporters after intestinal perfusion of a solution containing kaolinite. (a) Percentage of TAG disappeared from the perfusate after perfusion of Intralipid ${ }^{\circledR}$ solution in the control group (previously perfused with saline solution only) and in the kaolinite group (previously perfused with kaolinite in saline solution). (b) NEFA uptake (mmol/mg mucosa per min) in the control and kaolinite-perfused groups. (c) Plasma TAG concentration (mM) after the perfusion of Intralipid ${ }^{\circledR}$ solution in the control and kaolinite-perfused groups. (Since our rats underwent a $12 \mathrm{~h}$ fast before the perfusion, they presented plasma TAG concentrations close to zero before the perfusion in both groups). (d) Gene expression level of fatty acid transporter/cluster of differentiation 36 (FAT/CD36) in control and kaolinite-perfused rats. The control level was adjusted to 1. (e) Gene expression level of fatty acid binding protein (L-FABP) in control and kaolinite-perfused rats. The control level was adjusted to 1. (f) Gene expression level of fatty acid transport protein 4 (FATP4) in control and kaolinite-perfused rats. The control level was adjusted to 1. AU, arbitrary units. Values are means for six rats per group, with standard errors represented by vertical bars. * Mean value was significantly different from that of the control group $(P<0.05)$. 
during the same period was 25.6 (SEM 2.6) g/d ( $n$ 8) for the kaolinite group and 24.4 (SEM 1.7) g/d ( $n$ 10) for the control group $(P=0 \cdot 249)$. Body-mass gain was similar in the control and kaolinite groups after $28 \mathrm{~d}$. After 7 and $28 \mathrm{~d}$ kaolinite ingestion, SGLT1 and GLUT5 mRNA levels decreased significantly: by 1.8 -fold after 7 and $28 \mathrm{~d}$ for SGLT1 (Fig. 2(a)), and by 2.7 - and 2.4-fold after 7 and $28 \mathrm{~d}$, respectively, for GLUT5 (Fig. 2(c)). For GLUT5, this effect was confirmed and even drastically amplified at the protein level (Fig. 2(d)); indeed, we observed a 20- and a 100-fold decrease in GLUT5 protein expression after 7 and after $28 \mathrm{~d}$ kaolinite ingestion, respectively. SGLT1 protein expression, however, was not modified (Fig. 2(b)). Concerning the transporter GLUT2, kaolinite ingestion remained without effect at both mRNA and protein levels (Figs. 2(e), (f) and (g)).
Expression of fatty acid transporters after long-term kaolinite feeding

Kaolinite ingestion for 7 and $28 \mathrm{~d}$ caused a marked increase (about 1.5-fold) in plasma TAG concentration (Fig. 3(a)).

FAT/CD36 gene expression was not affected by kaolinite ingestion (Fig. 3(b)). However, kaolinite ingestion stimulated L-FABP gene expression (2- and 2.7-fold increase after 7 and $28 \mathrm{~d}$, respectively; Fig. 3(c)) and increased the cytoplasmic pool of L-FABP protein (by $2 \cdot 4$-fold after $7 \mathrm{~d}$ and by 2.9 -fold after $28 \mathrm{~d}$; Fig. 3(d)), but did not modify the expression of L-FABP in the brush-border membrane (Fig. 3(e)). Also, FATP4 gene expression showed a 1.7-fold increase after $28 \mathrm{~d}$ kaolinite ingestion (Fig. 3(f)), which was accompanied by a $1 \cdot 9$-fold increase in the amount of FATP4 (a)

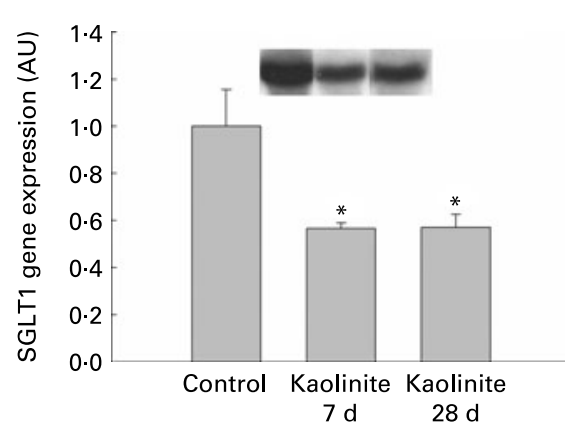

(c)

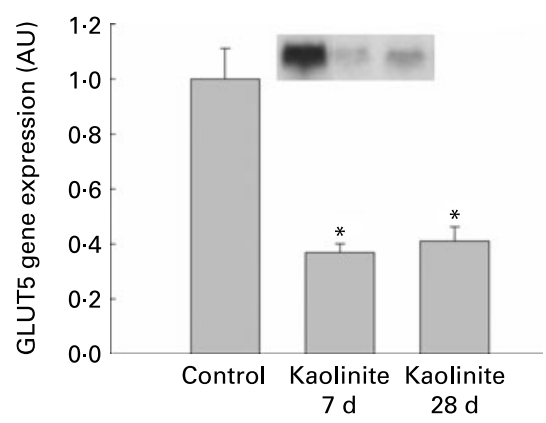

(e)

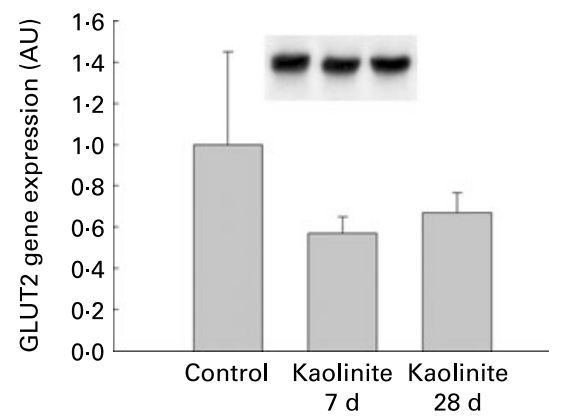

(b)

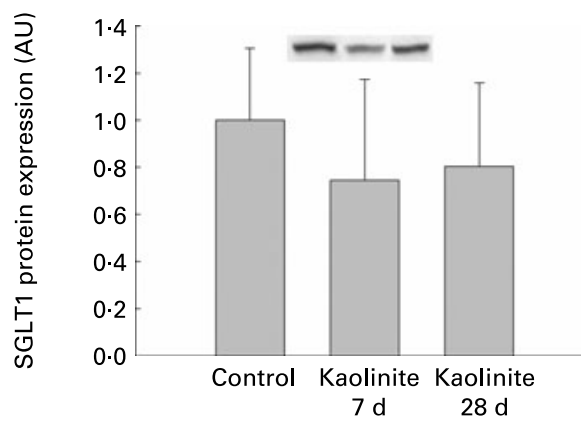

(d)

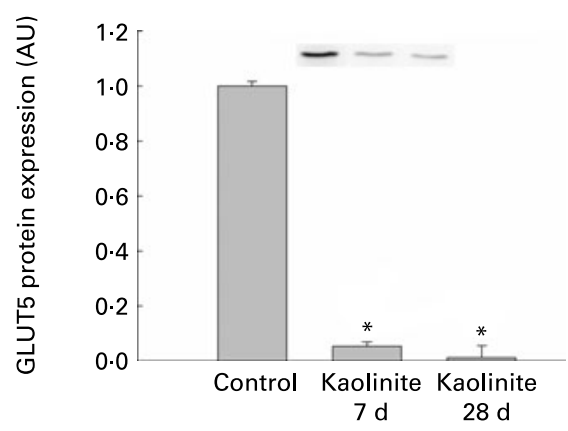

(f)

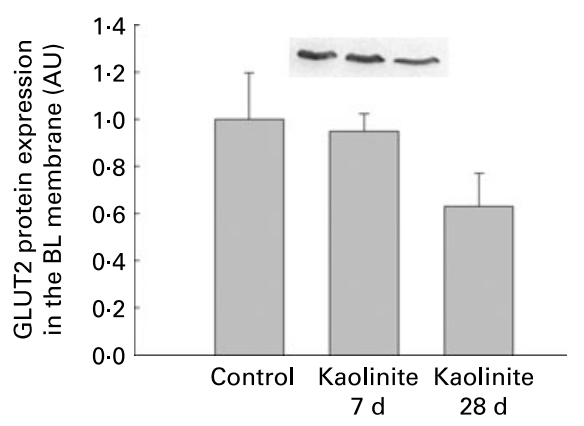

(g)

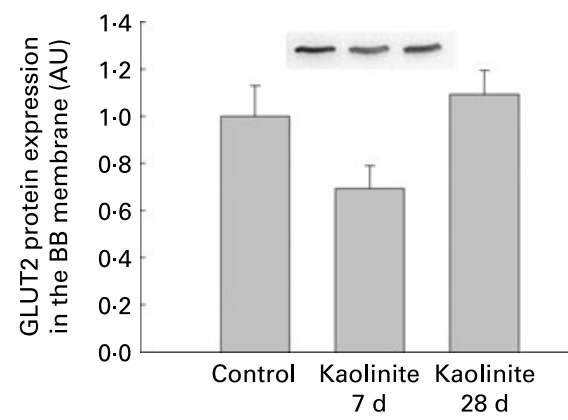

Fig. 2. Gene and protein expression levels of hexose transporters in control rats and in rats after 7 and $28 \mathrm{~d}$ kaolinite ingestion. (a) Na/glucose co-transporter 1 (SGLT1) gene expression. (b) SGLT1 protein expression. (c) GLUT5 gene expression. (d) GLUT5 protein expression. (e) GLUT2 gene expression. (f) GLUT2 protein expression in the basolateral (BL) membrane. (g) GLUT2 protein expression in the brush-border (BB) membrane. The control level was adjusted to 1. AU, arbitrary units. Values are means for five rats per group, with standard errors represented by vertical bars. ${ }^{*}$ Mean value was significantly different from that of the control group $(P<0.05)$. 
(a)

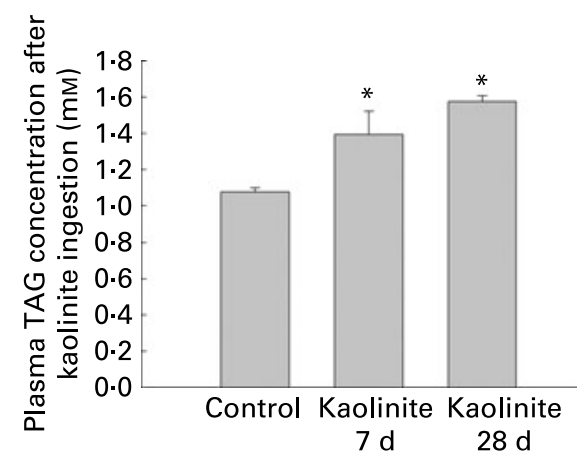

(c)

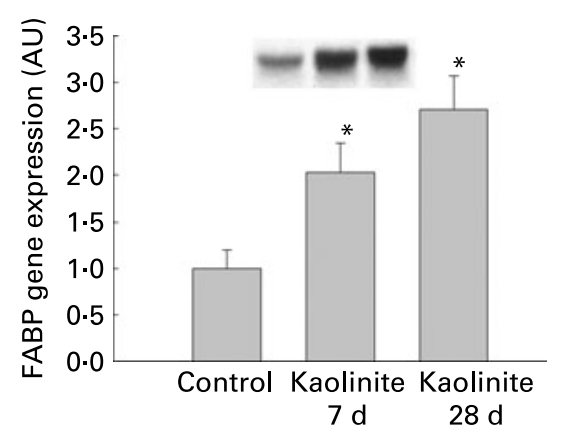

(f) (g)

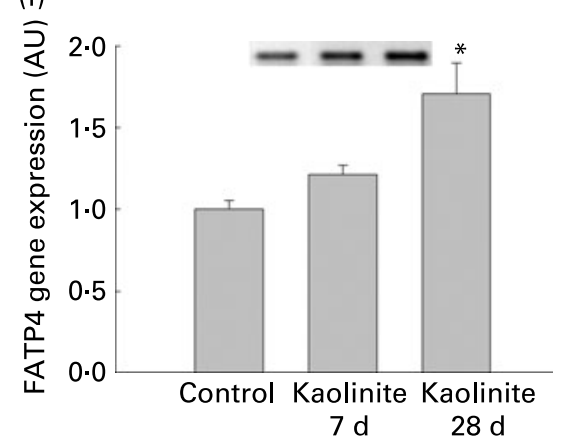

(d)
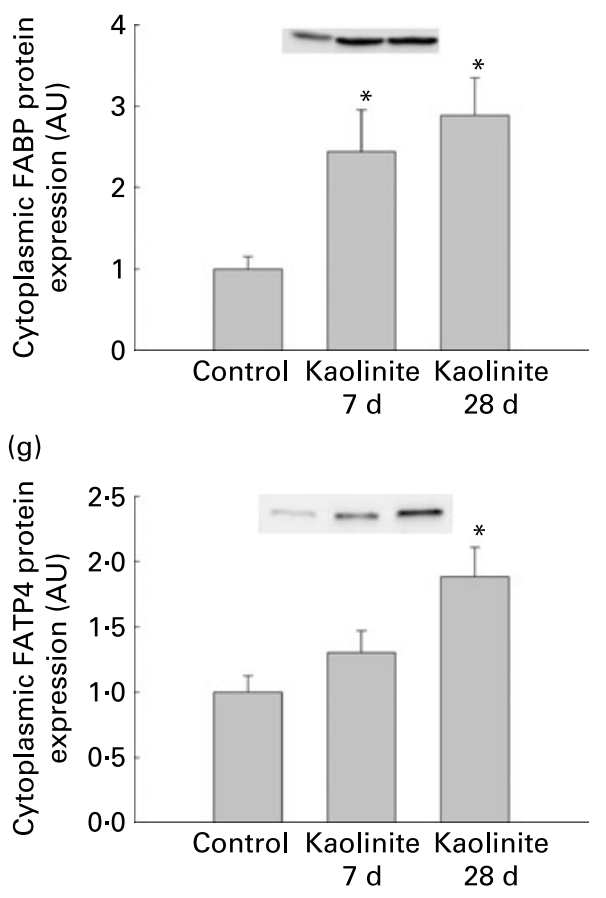

(b)

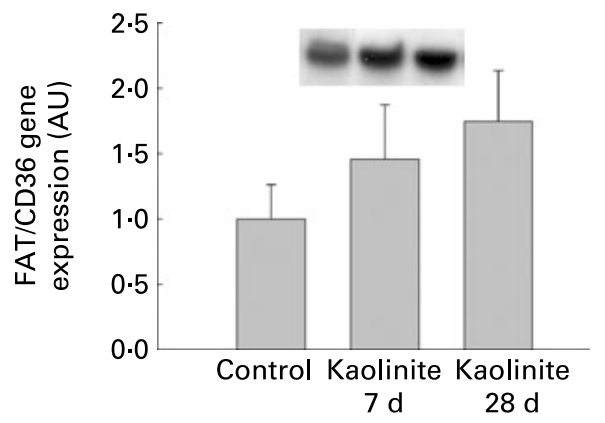

(e)

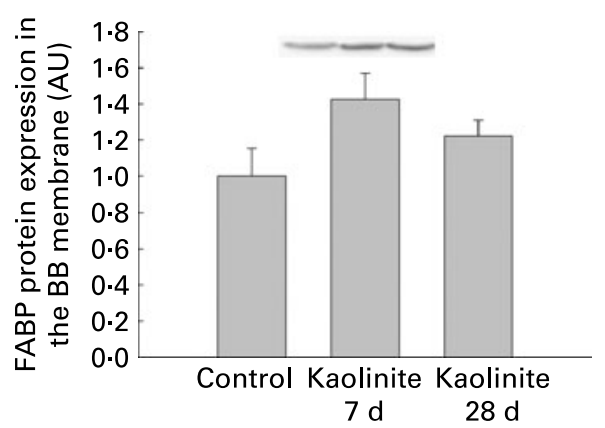

(h)

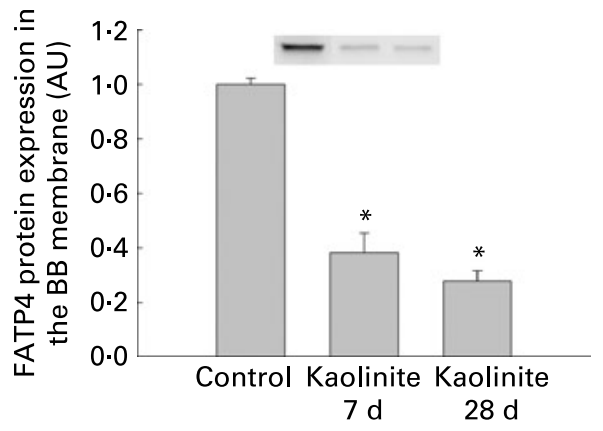

Fig. 3. Plasma TAG concentration and gene and protein expression levels of NEFA transporters in control rats and in rats after 7 and $28 \mathrm{~d}$ kaolinite ingestion. (a) Plasma TAG concentration (mM). (b) Fatty acid transporter/cluster of differentiation 36 (FAT/CD36) gene expression. (c) Fatty acid binding protein (L-FABP) gene expression. (d) L-FABP protein expression in the cytoplasm. (e) L-FABP protein expression in the brush-border (BB) membrane. (f) Fatty acid transport protein 4 (FATP4) gene expression. (g) FATP4 protein expression in the cytoplasm. (h) FATP4 protein expression in the BB membrane. For gene and protein expression, the control level was adjusted to 1. AU, arbitrary units. Values are means for five rats per group, with standard errors represented by vertical bars. ${ }^{*}$ Mean value was significantly different from that of the control group $(P<0.05)$.

protein in the cytoplasm (Fig. 3(g)). By contrast, FATP4 protein expression decreased in the brush-border membrane after 7 and $28 \mathrm{~d}$ kaolinite ingestion (Fig. 3(h)).

Lipase activity in the intestinal lumen after administration of kaolinite and olive oil by oral administration

Since we found a decrease in TAG concentration in the perfusate in the kaolinite group, we were interested in determining whether kaolinite affects TAG hydrolysis. In that way, we measured pancreatic lipase activity in the intestinal lumen in rats orally administered with either kaolinite in saline solution (kaolinite group) or only saline solution (control group), and then with olive oil. In this experimental setting, we observed a significant $1 \cdot 3$-fold increase in lipase activity in the kaoliniteadministered group (specific activity: 4429 (SEM 274) $\mu \mathrm{mol}$ of fatty acid released/min per $\mathrm{mg}$ protein in the kaolinite-administered group $v .3430$ (SEM $302 \mu \mathrm{mol}$ of fatty acid released $/ \mathrm{min}$ per mg protein in the control group); $P<0.05$ ).

\section{Gastric emptying and intestinal transit}

Gastric emptying and intestinal transit of methylene blue were measured in rats previously orally administered with kaolinite in saline solution (kaolinite group) or with saline solution only (control group). At $30 \mathrm{~min}$ after an oral administration of methylene blue, we observed a gastric emptying equal to $19 \%$ in the control group and to $7 \%$ (i.e. $2 \cdot 7$-fold less) in the kaolinite-treated group (Table 2). At the same time, the dye had reached 83.5 and $59.3 \%$ of the total length of the small intestine in the control and in the kaolinite group, respectively (Table 2 ). 
Table 2. Gastric emptying and intestinal transit of methylene blue in rats orally administered with saline solution (control) or with kaolinite in saline solution (kaolinite)

(Mean values with their standard errors for seven or eight rats per group)

\begin{tabular}{lcclll}
\hline & & & \multicolumn{2}{c}{$\begin{array}{c}\text { Intestinal transit } \\
\text { (\% of the total length of } \\
\text { the small intestine) }\end{array}$} \\
\cline { 2 - 3 } \cline { 5 - 6 } \cline { 5 - 6 } & Mean & SEM & Mean & SEM \\
\hline Control & 19.0 & 1.2 & 83.5 & 3.3 \\
Kaolinite & $7.0^{*}$ & 1.7 & $59.3^{*}$ & 6.1 \\
\hline
\end{tabular}

${ }^{*}$ Mean value was significantly different from that of the control group $(P<0.05)$.

\section{Discussion}

We show here that ingestion of kaolinite, a clay commonly used in human medicine, enhances intestinal TAG hydrolysis and NEFA absorption. This may be due to a slowing down of gastric emptying and intestinal transit caused by the presence of this clay in the digestive tract.

Perfusion of the small intestine with kaolinite solution did not modify glucose uptake rate. This is in contrast to the study of Dowling et al. ${ }^{(16)}$, showing increased glucose absorption after kaolinite feeding. This discrepancy may be explained by the difference in the kaolinite administration method and due to the amount of kaolinite administered: in the present study, the small intestine was perfused with a kaolinite solution, whereas Dowling et al. ${ }^{(16)}$ measured intestinal glucose uptake in rats fed for several weeks with a diet containing kaolinite powder (one part by weight of standard diet and two or four parts of kaolinite). Furthermore, the present results obtained after 7 and $28 \mathrm{~d}$ kaolinite ingestion cannot be compared with those of Dowling et al. ${ }^{(16)}$, since our rats ate spontaneously only a small amount of clay representing approximately $4 \%$ of the total amount ingested every day. Second, Dowling et al. ${ }^{(16)}$ studied glucose transport in the everted intestine, whereas we experimented in vivo without interrupting, as far as possible, the vascular and nervous connections.

As shown here, SGLT1 and GLUT5 gene expression decreased in rats fed with a diet containing $4 \%$ kaolinite during 7 and $28 \mathrm{~d}$. These results suggest that kaolinite ingestion may have long-term effects on hexose absorption. Furthermore, kaolinite ingestion may regulate SGLT1 and GLUT5 at a transcriptional level. The reason for these effects has yet to be determined. Kaolinite feeding does not cause intestinal hypertrophy ${ }^{(16)}$, which could have led to a relative decrease in the mRNA level of these genes when compared with the total amount of mRNA in the small intestine (i.e. in cells from the lamina propria, crypt cells, goblet cells, etc). An explanation could be the strong affinity of kaolinite for water $^{(12)}$ and thus, probably also for hexoses, which are very soluble in water because of their many hydroxyl groups. Also, it has been shown that D-glucose binds in a stereospecific manner to bentonite ${ }^{(5)}$. This may then lead to less SGLT1 and GLUT5 gene expression, since these are regulated by the amount of 'free' hexose in the lumen ${ }^{(31)}$. Indeed, SGLT1 gene expression is enhanced in glucose-enriched diets ${ }^{(31)}$, whereas fructose but not glucose increases the transcription of the
GLUT5 gene ${ }^{(32)}$. In kaolinite-fed rats, SGLT1 mRNA decreased whereas its protein expression did not vary. This could be due to an increase in SGLT1 mRNA half-life, since expression of SGLT1 is known to be regulated post-transcriptionally at the level of mRNA stability ${ }^{(3,34)}$.

By contrast, kaolinite may improve TAG digestive efficiency and NEFA uptake. First, kaolinite enhances TAG hydrolysis. This could be due either to an increased pancreatic secretion of lipase into the small-intestinal lumen, or to increased pancreatic lipase activity. We would favour the latter hypothesis, since clay minerals are known to be an appropriate substratum for enzymes: diosmectite shows a dose-dependent capacity to adsorb some enzymes in vitro ${ }^{(6)}$; kaolinite feeding in the rat has been shown to increase the activity of leucine amino-peptidase and of several dehydrogenases $^{(7)}$. In the present study, kaolinite may induce an increase in the activity of pancreatic lipase, a water-soluble enzyme hydrolysing TAG at an oil-water interface. This could be linked again to the fact that kaolinite easily adsorbs water $^{(12)}$, which is required for the structural integrity of the enzyme ${ }^{(35)}$, and to its high surface area per unit mass. Clays also have binding properties for bile salts ${ }^{(36)}$. All these physical properties may thus trigger pancreatic lipase activity.

Second, kaolinite perfusion stimulated NEFA uptake. However, plasma TAG concentration remained unchanged. It has been shown elsewhere that the synthesis and/or secretion of chylomicrons are a rate-limiting step of NEFA absorption, leading to a physiological accumulation of TAG in the intestinal mucosa during intestinal perfusion of $\mathrm{TAG}^{(37)}$. This could explain the observed increase in NEFA uptake in rats perfused with kaolinite without significant changes in triacylglycerolaemia. However, after long-term exposure to kaolinite, i.e. after long-term exposure of the enterocytes to high luminal NEFA concentrations (due to increased TAG hydrolysis) plasma TAG concentration increased. This is in accordance with the study of Cartwright \& Higgins ${ }^{(38)}$ showing that feeding a fat-enriched diet for 2 weeks significantly stimulated the ability of isolated enterocytes to synthesise and secrete chylomicrons in comparison with feeding a single dose of lipid.

NEFA might diffuse mainly passively across enterocyte apical membranes, a process that is driven by a concentration gradient, rather than via a protein-facilitated membrane transport system. Indeed, expression of the main fatty acid transporters (CD36, L-FABP and FATP4) in the brush-border membrane did not vary or was even reduced after kaolinite treatment. In the diffusion model, NEFA uptake rate is directly correlated with the surface area of the brush-border membrane. Kaolinite supplementation during $28 \mathrm{~d}$ in rats induces a $14.5 \%$ increase in villi thickness under the villi tips, but a $20 \%$ decrease in microvilli length ( $\mathrm{F}$ Reichardt, unpublished results). From these results, we cannot conclude whether kaolinite ingestion during $28 \mathrm{~d}$ in rats causes a decrease or an increase in the absorptive surface area. However, the present results showing a decrease in gastric emptying and transit time are in favour of an increase of lipid absorption. Indeed, the interaction of nutrients with small-intestinal receptors regulates gastric emptying and stimulates the release of gastrointestinal hormones including cholecystokinin and glucagonlike peptide-1. In healthy subjects, intraduodenal infusion of fat slows gastric emptying ${ }^{(39)}$. This effect is associated with 
an increase in pyloric motility ${ }^{(40)}$. Furthermore, the slowing of gastric emptying by fat is dependent on lipolysis of TAG to fatty acids ${ }^{(4)}$. Therefore, one hypothesis is that ingestion of clay increases the hydrolysis of fat and, therefore, increases its absorption. The precise mechanism involved remains to be elucidated.

After uptake, rapid esterification of NEFA by long-chain acyl-CoA synthetase would prevent efflux, whereas rapid binding of NEFA and of their CoA esters by FABP would act as an intracellular NEFA buffer ${ }^{(42,43)}$. More recently, FATP4 has been localised within the enterocyte endoplasmic reticulum and has a CoA acylase function ${ }^{(25)}$. The correlation of fatty acid uptake with FATP4 expression has been proposed to be due to the intracellular trapping of the fatty acid as acyl CoA, and not to an apical transport function. In the present study, an increase in FATP4 and L-FABP gene expressions after kaolinite supplementation has been observed. It is known that the liver type of FABP, which is mainly expressed in the proximal jejunum (our model), is transcriptionally up-regulated by long-chain fatty acid molecules ${ }^{(44)}$. We then separated the brush-border membrane proteins from other mucosal proteins before performing Western blot analysis. We could observe an increase in FATP4 and L-FABP protein expressions in the cytoplasm but not in the brush-border membrane from kaolinite-supplemented rats, confirming the role of these proteins in the intracellular trapping of NEFA. A decrease in microvilli length after $28 \mathrm{~d}$ of kaolinite complementation (F Reichardt, unpublished results) could finally explain the decrease in FATP4 within the brush-border membrane.

Rats fed an elemental diet with $10 \%$ kaolinite (w/w) show greater body-mass gain after $14 \mathrm{~d}^{(45)}$. Based on our data, the explanation might then be that increased NEFA absorption in kaolinite-fed rats leads to an increase in lipid accretion. The next step is therefore to investigate the effect of kaolinite ingestion on lipid accretion, since geophagy, which is usually practised by socially disadvantaged cultural and ethnic groups living in the tropics ${ }^{(46,47)}$, might not only reduce the energetic cost of diarrhoea but also optimise absorption of high-energy nutrients such as NEFA.

\section{Acknowledgements}

We thank Marine Delihu and Luc Haar for their excellent technical assistance.

Financial support for the present study was provided by the French Agence Nationale pour la Recherche (ANR).

C. H. conceived of and designed the study, collected and assembled the data, analysed and interpreted the data, and wrote and revised the manuscript; F. R. provided the study material; Y. L. M., N. L. and J.-H. L. wrote and revised the manuscript; F. A. revised the manuscript; H. O. conceived of and designed the study, collected the data, analysed and interpreted the data, and wrote and revised the manuscript.

The authors have no conflicts of interest to disclose.

\section{References}

1. Beck IT, Jenkins N, Thurber L, et al. (1977) Methods for the study of antidiarrheal agents. Study of commonly used protective and adsorbent agents. $J$ Med 8, 135-158.
2. Guarino A, Bisceglia M, Castellucci G, et al. (2001) Smectite in the treatment of acute diarrhea: a nationwide randomized controlled study of the Italian Society of Pediatric Gastroenterology and Hepatology (SIGEP) in collaboration with primary care pediatricians. SIGEP Study Group for Smectite in Acute Diarrhea. J Pediatr Gastroenterol Nutr 32, 71-75.

3. Moré J, Bénazet F, Fioramonti J, et al. (1987) Effects of treatment with smectite on gastric and intestinal glycoproteins in the rat: a histochemical study. Histochem J 19, 665-670.

4. Bergaya F, Theng BKG \& Lagaly G (2006) Developments in Clay Science, vol. 1, Handbook of Clay Science. Amsterdam: Elsevier.

5. Bondy SC \& Harrington ME (1979) L-Amino acids and L-glucose bind stereospecifically to a colloidal clay. Science $\mathbf{2 0 3}$, $1243-1244$.

6. González R, de Medina FS, Martínez-Augustin O, et al. (2004) Anti-inflammatory effect of diosmectite in hapten-induced colitis in the rat. Br J Pharmacol 141, 951-960.

7. Riecken EO, Dowling RH, Booth CC, et al. (1965) Histochemical changes in the rat small intestine associated with enhanced absorption after high bulk feeding. Enzymol Biol Clin (Basel) 5, 231-244.

8. Vermeer DE \& Ferrell RE Jr (1985) Nigerian geophagical clay: a traditional antidiarrheal pharmaceutical. Science 227, 634-646.

9. Kasi M, Kausar P, Naz R, et al. (1995) Treatment of diarrhoea in infants by medical doctors in Balochistan, Pakistan. $J$ Diarrhoeal Dis Res 13, 238-241.

10. Aufreiter S, Hancock RGV, Mahaney WC, et al. (1997) Geochemistry and mineralogy of soils eaten by humans. Int $J$ Food Sci Nutr 48, 293-305.

11. Mahaney WC, Milner MW, Hs M, et al. (2000) Mineral and chemical analysis of soils eaten by humans in Indonesia. Int $J$ Environ Health Res 10, 93-109.

12. Klein C \& Hurlbut CS (1993) Manual of Mineralogy, 21st ed. New York: John Wiley and Sons.

13. Brigatti MF, Galan E \& Theng BKG (2006) Structures and mineralogy of clay minerals. In Developments in Clay Science, vol. 1, Handbook of Clay Science, pp. 19-86 [F Bergaya, BKG Theng and G Lagaly, editors]. Amsterdam: Elsevier.

14. Dominy NJ, Davoust E \& Minekus M (2004) Adaptive function of soil consumption: an in vitro study modeling the human stomach and small intestine. J Exp Biol 207, 319-324.

15. Phillips TD (1999) Dietary clay in the chemoprevention of aflatoxin-induced disease. Toxicol Sci 52, Suppl. 2, 118-126.

16. Dowling RH, Riecken EO, Laws JW, et al. (1967) The intestinal response to high bulk feeding in the rat. Clin Sci 32, 1-9.

17. Debnam ES \& Levin RJ (1975) An experimental method of identifying and quantifying the active transfer electrogenic component from the diffusive component during sugar absorption measured in vivo. J Physiol 246, 181-196.

18. Kellett GL \& Helliwell PA (2000) The diffusive component of intestinal glucose absorption is mediated by the glucose-induced recruitment of GLUT2 to the brush-border membrane. Biochem J 350, 155-162.

19. Kellett GL (2001) The facilitated component of intestinal glucose absorption. J Physiol 531, 585-595.

20. Thorens B, Cheng ZQ, Brown D, et al. (1990) Liver glucose transporter: a basolateral protein in hepatocytes and intestine and kidney cells. Am J Physiol 259, C279-C285.

21. Hirsch D, Stahl A \& Lodish HF (1998) A family of fatty acid transporters conserved from mycobacterium to man. Proc Natl Acad Sci U S A 95, 8625-8629.

22. Stahl A, Hirsch DJ, Gimeno RE, et al. (1999) Identification of the major intestinal fatty acid transport protein. Mol Cell 4, 299-308. 
23. Stahl A, Gimeno R, Tartaglia LA, et al. (2001) Fatty acid transport proteins: a current view of a growing family. Trends Endocrinol Metab 12, 266-273.

24. Bonen A, Han XX, Habets DD, et al. (2007) A null mutation in skeletal muscle FAT/CD36 reveals its essential role in insulinand AICAR-stimulated fatty acid metabolism. Am J Physiol Endocrinol Metab 292, E1740-E1749.

25. Milger K, Herrmann T, Becker C, et al. (2006) Cellular uptake of fatty acids driven by the ER-localized acyl-CoA synthetase FATP4. J Cell Sci 119, 4678-4688.

26. Fergani A, Oudart H, Gonzalez De Aguilar JL, et al. (2007) Increased peripheral lipid clearance in an animal model of amyotrophic lateral sclerosis. J Lipid Res 48, 1571-1580.

27. Chomczynski P \& Sacchi N (1987) Single-step method of RNA isolation by acid guanidinium thiocyanate-phenol-chloroform extraction. Anal Biochem 162, 156-159.

28. Trayhurn P, Thomas ME, Duncan JS, et al. (1995) Ultra-rapid detection of mRNAs on Northern blots with digoxigeninlabelled oligonucleotides and 'CDP-Star', a new chemiluminescence substrate. Biochem Soc Trans 23, 494S.

29. Schmitz J, Preiser H, Maestracci D, et al. (1973) Purification of the human intestinal brush border membrane. Biochim Biophys Acta 323, 98-112.

30. Hames BD (1996) One dimensional polyacrylamide gel electrophoresis. In Gel Electrophoresis of Proteins: A Practical Approach, 2nd ed., pp. 1-52 [BD Hames and D Rickwood, editors]. Oxford: Oxford University Press.

31. Goda T (2000) Regulation of the expression of carbohydrate digestion/absorption-related genes. Br J Nutr 84, Suppl. 2, S245-S248.

32. Goda T, Yasutake H, Tanaka T, et al. (1999) Lactase-phlorizin hydrolase and sucrase-isomaltase genes are expressed differently along the villus-crypt axis of rat jejunum. $J$ Nutr 129, $1107-1113$

33. Shioda T, Ohta T, Isselbacher KJ, et al. (1994) Differentiationdependent expression of the $\mathrm{Na}^{+}$/glucose cotransporter (SGLT1) in LLC-PK1 cells: role of protein kinase $\mathrm{C}$ activation and ongoing transcription. Proc Natl Acad Sci U S A 91, 11919-11923.

34. Peng H \& Lever JE (1995) Post-transcriptional regulation of $\mathrm{Na}^{+} /$glucose cotransporter (SGTL1) gene expression in LLCPK1 cells. Increased message stability after cyclic AMP elevation or differentiation inducer treatment. $J$ Biol Chem 270, 20536-20542.
35. Yeşiloğlu Y (2005) Utilization of bentonite as a support material for immobilization of Candida rugosa lipase. Process Biochem 40, 2155-2159.

36. Vatier J, Olivier JF, Vitre MT, et al. (1989) Influence of pH in the adsorption capacity of bile salts and lysolecithins in vitro by antacids containing clay and/or aluminium. Gastroenterol Clin Biol 13, 445-451.

37. Wu AL \& Bennett Clark S (1976) Resistance of intestinal triglyceride transport capacity in the rat to adaptation to altered luminal environment. Am J Clin Nutr 29, 157-168.

38. Cartwright IJ \& Higgins JA (1999) Increased dietary triacylglycerol markedly enhances the ability of isolated rabbit enterocytes to secrete chylomicrons: an effect related to dietary fatty acid composition. J Lipid Res 40, 1858-1866.

39. Heddle R, Collins P, Dent J, et al. (1989) Motor mechanisms associated with slowing of the gastric emptying of a solid meal by an intraduodenal lipid infusion. $J$ Gastroenterol Hepatol 4, 437-447.

40. Fone DR, Horowitz M, Dent J, et al. (1989) Pyloric motor response to intraduodenal dextrose involves muscarinic mechanisms. Gastroenterology 97, 83-90.

41. Raybould HE, Meyer JH, Tabrizi Y, et al. (1998) Inhibition of gastric emptying in response to intestinal lipid is dependent on chylomicron formation. Am J Physiol 2, R1834-R1838.

42. Knudsen J (1990) Acyl-CoA-binding protein (ACBP) and its relation to fatty acid-binding protein (FABP): an overview. Mol Cell Biochem 98, 217-223.

43. Besnard P, Niot I, Poirier H, et al. (2002) New insights into the fatty acid-binding protein (FABP) family in the small intestine. Mol Cell Biochem 239, 139-147.

44. Poirier H, Niot I, Monnot MC, et al. (2001) Differential involvement of peroxisome-proliferator-activated receptors $\alpha$ and $\delta$ in fibrate and fatty-acid-mediated inductions of the gene encoding liver fatty-acid-binding protein in the liver and the small intestine. Biochem J 355, 481-488.

45. Sakata T (1986) Effects of indigestible dietary bulk and short chain fatty acids on the tissue weight and epithelial cell proliferation rate of the digestive tract in rats. J Nutr Sci Vitaminol 32, $355-362$.

46. Abrahams PW \& Parsons JA (1996) Geophagy in the tropics a literature review. Geogr J 162, 63-72.

47. Simon SL (1998) Soil ingestion by humans: a review of history, data, and etiology with application to risk assessment of radioactively contaminated soil. Health Phys 74, 647-672. 